\title{
Problem-Orientated Antenatal Notekeeping: A Useful Primary Health Care Tool
}

\author{
J.V. Larsen M.B. Ch.B., M.R.C.O.G., \\ Department of Obstetrics and Gynaecology, King Edward VIII Hospital.
}

\section{OPSOMMING}

'n Stelsel van probleemgerigte aantekeninge t.o.v. voorgeboortesorg word beskryf. Hierdie stelsel is waardevol vir vroedvroue wat primêre verloskundige sorg verskaf wanneer dit gepaard gaan met duidelike voorskrifte vir elke probleem of risikofaktor wat opduik. Dit bevorder kommunikasie tussen verwyskliniek en basishospitaal en is ' $n$ help by die opleiding van die kliniekvroedvrou.

\section{INTRODUCTION}

$\mathbf{I}^{\prime}$ $\Gamma$ HAS recently been demonstrated that about 56 percent of patients delivering in a rural obstetric unit had significant risk factors, and that 85 percent of these could have been detected by meticulous antenatal screening before the onset of labour. These figures show that the average rural obstetric unit in South Africa is dealing with a large percentage of high risk patients. In this work, it is hampered by:

1. Communications problems: i.e. bad roads, long distances. and unpredictable telephones.

2. A serious shortage of medical staff resulting in primary obstetric care being delivered by midwives with minimal medical supervision.

It is logical to expect that early detection of the antenatal patient at risk will greatly improve the care which can be offered the patient because she can be:

1. Warned early in the pregnancy that hospital delivery will be necessary.

2. Selected for special attention from the doctor, often before complications develop.

3. Moved to a waiting mothers" area in or near the hospital. and thus be near enough to receive optimal care in hospital from the onset of labour. In a city community obstetric programme, the patient can be transferred timeously to the antenatal clinic at the base hospital for continued care

\section{PATIENT STREAMING}

The concept of early detection of antenatal abuormalities in order to determine the direction of subsequent antenatal care is referred to as "streaming" of antenatal patients. If streaming of patients is to be effective, it is essential that:

1. The documentation of the risk factor recognised in any given patient should be clear. and

2. The direction of management necessitated by that risk factor should be clearly indicated. This latter aim can be achieved in part by placing the patient into categories according to her problem. The simplest set of categories to use is set out below:

A. Normal - (no risk factor) - clinic delivery

B. "At risk" pregnancy - clinic delivery with special protocol

- hospital delivery with special protocol

- "Doctor's patient"

The primary care midwife should be trained to categorise each patient in the antenatal clinic by the 38th week of pregnancy. and to make decisions about her management accordingly. In order to assist her in this task, the antenatal record should be so designed as to oblige her, when filling it in, to arrive at a diagnosis about the patient's status by this stage in her pregnancy, and to indicate the direction of her management accordingly. In order to achieve this, the record should contain the following blocks:

1. A diagnosis block (see Figure 1)

The aim of this block is to encourage the midwife to review the patient's record critically at each visit, but especially at 36-38 weeks. when the decision as to the place of delivery must be made for most patients. Such a review must constitute an intelligent appraisal of the whole record. looking for patterns of factors which may together make up a major risk factor. For example: 
Figure 1

\section{Antenatal Examinations}

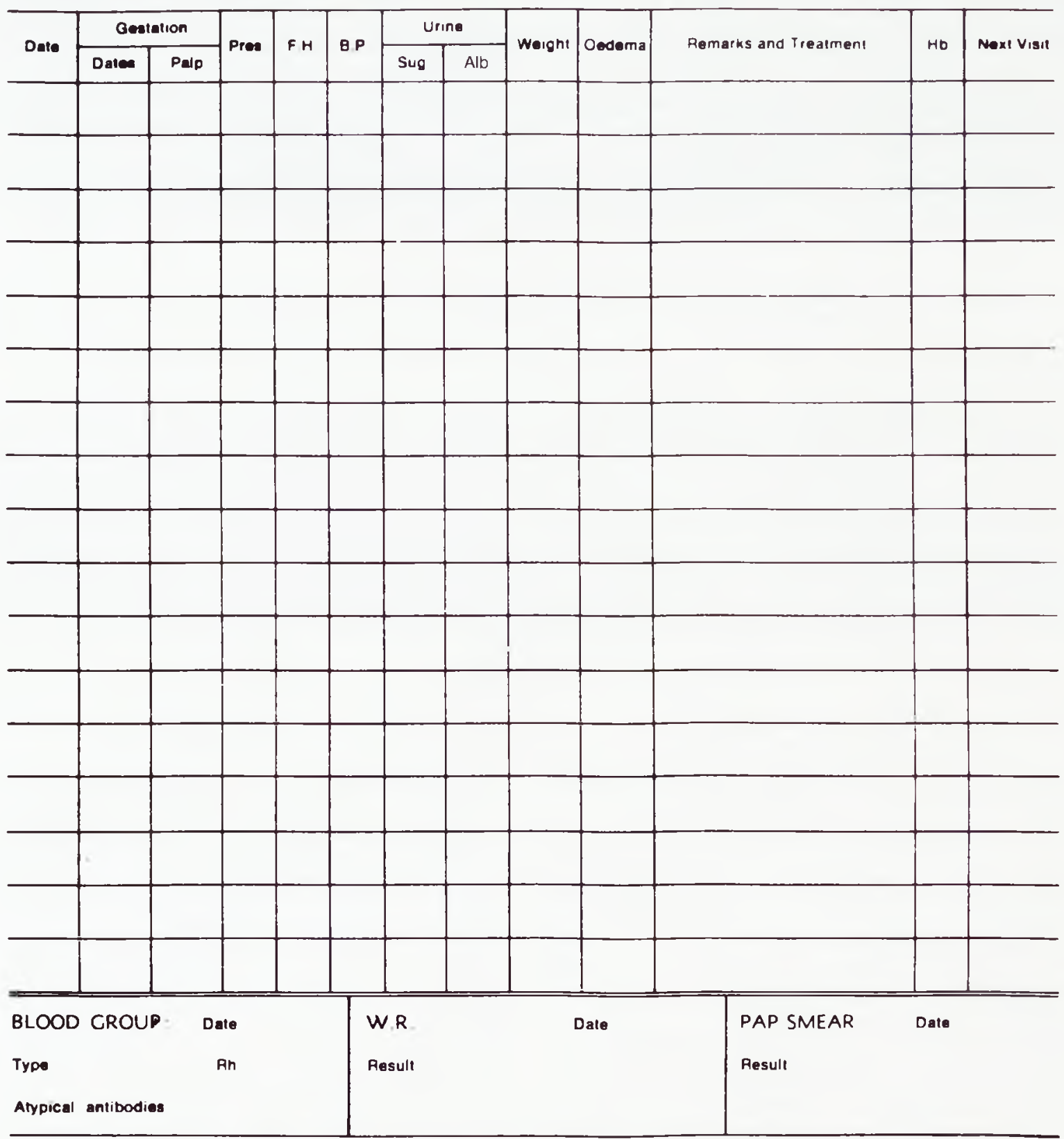

DIAGNOSIS aT 38 WEEKS: NORMAL|AT RISK PREGNANCY

RISK FACTORS:

RECOMMENDATIONS

\section{CATEGORY \\ Clinic \\ Delivery \\ Doctors \\ Patient}

Hospital

Delivery 
1. Gravida 1

Age 35 years

Married 12 years

2. Gravida 6. Para 5

Age 40 years

1 Neonatal death

1 Stillbirth

3. Gravida 2. Para 1

Age 20 years

Single

4. Gravida 1. Para 0

Age 15 years

Obstetric conjugate $8.5 \mathrm{cms}$

Rhesus negative means

Important risk factor

(Subfertility — "elderly primip")

Major risk factors

(Grande multip -- elderly -

possibly diabetic)

Major risk factor

(Previous Caesarean section)

3 risk factors

(Teenage primipara. small pelvis.

means
2. A "Risk Factor"' Block (see Figure 1)

Having recognised the pattern constituting a major risk. it is important that there be a single place in the record where the risk factor recognised can be documented. This in order that subsequent observers can be alerted to continue management in the appropriate direction.

3. A Recommendations Block see Figure 1)

Recommendations about management arising from the assessment made in this way should also be documented in a standard place in the antenatal record. This block should be divided into two distinct parts. The first should indicate where the patient should be delivered (in clinic or in hospital) and whether she can be looked after there by the midwives or be a doctor"s patient. In Figure I for instance, the recommended place of confinement is indicated by encircling either "clinic delivery" or "hospital delivery" with a bold red line.

Space is also made available for other specific recommendations about the management of the patient. It is a valuable discipline that these be recorded where indicated during the antenatal period. This block can thus serve as a reminder of important points in management to the person looking after the patient amid the stresses of a busy labour ward. When correctly filled in. it also has considerable educative value for new staff entering the service.

RISK FACTOR LINKED MANAGEMENT PROTOCOLS

Clearly, if accurate direction of management is to be achieved, the midwife doing the antenatal screening must have appropriate "risk factor linked" management protocols available to her. Such protocols must include:

1. A definition of the risk factor so that she knows what she is looking for.

2. The category into which the patient with the risk factor should be placed. (Hospital delivery by nurses, or doctor's patient. or clinic delivery with special protocols).

3. The action required of her in regard to the management of such a patient, including such details as the timing and method of referral of the patient to the hospital. any investigations required and their timing. and any special details which will need attention from a midwife at the clinic level before referral.

4. In a rural hospital unit, a summary of the important points in the management of such a patient before, during and after labour could be included for the guidance of medical and nursing personnel on duty when she delivers.

An example of such a protocol is given below:

\section{CLINIC PROTOCOL TEENAGE PREGNANCY}

\section{Diagnosis}

Pregnancy occurring in a girl of 17 years of age or younger. Category

Hospital delivery.

\section{Action at the clinic}

1. Obtain written consent from a parent or guardian, to your giving antenatal care, family planning advice. and transferring the patient to hospital for delivery. Consent must also include permission for any operations necessary to safe delivery. 
2. Give special attention to teaching mothercraft skills. and to motivating the patient to make full use of the well baby clinic.

3. Be prepared to involve the social worker if there is evidence of serious social disruption.

4. See frequently, looking especially for:

Syphilis

Anaemia

Pre-eclampsia.

Refer for admission if there is only mild evidence of hypertension and proteinuria.

5. Admit to waiting mothers" area at 38 weeks

\section{Hospital Management:}

1. Assess the pelvis with care - cephalo-pelvic disproportion is common.

2. Take care to exclude abnormal patterns of uterine action.

3. Prevent eclampsia by treating even mild pre-eclampsia seriously.

4. Keep at least five days post-partum in order to supervise breast-feeding and teach mothercraft skills adequately.

5. Ensure adequate arrangements are made for family planning and well baby clinic care before discharge.

Convenient methods of making such protocols available are card index or book systems, each card or page dealing with one subject. To return to the patients mentioned earlier. their assessments according to clinic protocols could read as follows:

1. The patient is Gravida 1,35 years of age, and married for 12 years.

Diagnosis at 38 weeks: Normal/At Risk pregnancy

Risk factors: Elderly Primipara; Sub-fertility

Category: Clinic Hospital Doctor's

\section{Delivery Delivery Patient}

Recommendations: Admit waiting mothers' area at 36 weeks. Do not allow to go post-mature. Caesarean section if poor progres: in labour.

Immediate action at the clinic level in this patient would include a clear explanation as to why she must deliver in hospital, with care in ensuring that the patient knows how and when to go there.

2. The patient is a 40-year-old Gravida 6, Para 5, who has had one neonatal death and one stillbirth. Her assessment may read as follows:

Diagnosis at 38 weeks: Normal/At Risk pregnancy

Risk factors: Grande Multipara, 40 years of age, Poor obstetric history

Category: Clinic

Delivery
Doctor's

Patient
Recommendations: Attend hospital immediately for investigations (GTT). Admit wating area at 36 weeks.

Immediate action at the clinic level in this patient would include a discussion as to why hospital delivery is necessary, and firm motivation of the patient toward accepting lubal ligation. The third line in recommendat tions would be filled in by the doctor once his decision about the timing and route of delivery of the patient has been made.

\section{DISCUSSION}

This system of notekeeping has a number of important advantages for a community obstetric programme:

1. It helps in achieving clear communications between referring clinic and base hospital. It is obvious even to the new medical officer, unfamiliar with the management policies of the unit why, he patient is referred and who is expected to look after her on arrival in the hospital. This results in a much higher standard of care.

2. The midwife rapidly becomes familiar with treatment protocols because she is constantly initiating them. In addition, a high level of peer teaching and surveillance is easy to achieve when recognised risk factors are properly documented and the direction of treatment clearly indicated.

3. This method of documentation also has the advantage that it enables the supervising doctor to recognise more easily whether any mismanagement is due to patient or staff failure. In practice. the method removes the need for unpleasant inquisitions to establish the facts, and thus frank discussion of staff failure can begin in a better atmosphere.

4. Use of this system makes the monitoring of the primary care midwife's work relatively easy. It is possible by simply glancing through the record to note whether shi has appreciated the problem presented by any given patient, and whether she is taking the appropriate action. In the case of a peripheral clinic which the doctor visits only in a supervisory and consultative capacity, it becomes possible for him to work through the antenatal records of the patients attending that clinic with the sister in charge, discussing problems missed, and using these records as a teaching aid. as together the doctor and the midwife fill in categories and recommendations.

My thanks are due to Professor R.H. Philpott and Dr S. Ross for their criticism and assistance in the preparation of this paper.

\section{REFERENCE:}

I. Larsen. J.V.: A Survey of a Rural Zulu Obstetric Population. Paper awaiting publication. 